\title{
ОБЩЕЕВРОПЕЙСКИЕ ВЫБОРЫ 2019 ГОДА: ПРЕДВАРИТЕЛЬНЫЕ ПРОГНОЗЫ И ВОЗМОЖНЫЕ ПЕРСПЕКТИВЫ
}

\begin{abstract}
Аннотация. В мае 2019 г. в странах Европейского союза пройдут очередные выборы депутатов Европарламента - главного представительного органа союза. С учётом ряда недавних громких событий, потрясших Евросоюз - брекзита, прихода к руководству ряда стран членов ЕС (Австрии, Венгрии, Италии, Польши) евроскептических и популистских сил, обострения отношений с бывшим главным партнёром Евросоюза - США и с неизменным оппонентом в лице России, результаты этих выборов малопредсказуемьл. В данной статье автор проанализировал возможное влияние этих событий на итоги предстоящих выборов и попытался дать предварительный прогноз и их результаты.
\end{abstract}

Ключевые слова: Европейский союз, Европарламент, европейские партии, европейские выборы, брекзит, «ведущиий кандидат» (Spitzenkandidat).

Европейские выборы пройдут с 23 по 26 мая 2019 г. в 27 государствах - членах Союза. За полгода до проведения эти выборы вызывают гораздо больше внимания в обществе, в том числе в научной среде, чем предыдущие (2014 и 2009 гг.).

В конце 2018 г. прошли конгрессы (заседания советов) ведущих европейских политических партий (Европейская народная партия (ЕНП) - 7-8 ноября, Альянс либералов и демокра тов за Европу (АЛДЕ) - 8-10 ноября, Европейская партия зелёных (ЕПЗ) - 27 ноября, Партия европейских социалистов (ПЕС) - 7-8 декабря), которые стали первым этапом начавшейся избирательной кампании. По результатам этих форумов некоторые из партий выдвинули своего кандидата (кандидатов) на пост будущего Председателя Европейской Комиссии (ЕК), которого будущий состав Европарламента (ЕП) изберёт в рамках концепции «Spitzenkandidat» («ведущий кандидат»). Эта концепция, поддержанная депутатами Европарламента, предусматривает, что каждая европартия до начала избирательной кампании представит своего кандидата на пост Главы ЕК, и только из их числа будет избираться новый Председатель ЕК ${ }^{1}$. ЕНП в качестве своего кандидата выдвинула М. Вебера ${ }^{2}$, представителя ХДС и руководителя фракции ЕНП в нынешнем составе ЕП. ПЕС в качестве своего кандидата предложила Ф. Тиммерманса, нынешнего заместителя Председателя ЕК, представляющего Партию труда из Нидерландов.

Проведённый в мае 2018 г. опрос Евробарометра показал, что 49\% из 27601 опрошенных из всех 28 стран - членов ЕС считают, что процесс Spitzenkandidat поможет им более осознанно проголосовать на следующих европейских выборах. При этом 70\% уверены, что на этих выборах необходимо будет провести «реальные дебаты» по общеевропейским вопро-

(С Гуселетов Борис Павлович, доктор политических наук, ведущий научный сотрудник Центра партийно-политических исследований ИЕ РАН, профессор базовой кафедры ИЕ РАН в РГСУ. Адрес: 125009, Россия, Москва, ул. Моховая, д. 11, стр. 3. E-mail: bgusletov@mail.ru.

DOI: http://dx.doi.org/10.15211/vestnikieran620184754

${ }^{1}$ Потемкина О.Ю. Европейский парламент 2019: подготовка к выборам. Журнал Современная Европа. 2-18. №4. C. 35-45. URL: http://www.sov-europe.ru/2018/04-2018.pdf (дата обращения: 21.12.2018 г.).

2 Web site of European People party. URL: https://weber.epp.eu/get_to_know_me (дата обращения: 21.12.2018 г.). 
сам среди представителей ведущих европейских партий.

\section{Влияние брекзита на электоральные шансы ведущих европартий}

Официальные переговоры между ЕС и Великобританией об условиях выхода последней из Союза завершены и теперь ясно, что Великобритания покинет Европейский союз не позднее 29 марта 2019 г. когда истечёт двухлетний период с того момента, как британцы 29 марта 2017 г. инициировали ст. 50 Договора о EC ${ }^{1}$. Следовательно, она больше не будет иметь собственных депутатов Европарламента (ДЕП) и своего еврокомиссара. Уход 73 британских депутатов из Европарламента в основном затронет три существующие политические группы в Европарламенте (ЕП).

Во-первых, это группа «Социалистов и демократов» (СиД) проевропейской ПЕС, которая потеряет 20 депутатов Европарламента от «Лейбористской партии» Великобритании из 187 , входящих в эту группу ${ }^{2}$. С учётом того, что другие ведущие партии-члены этой группы - Социал-демократическая партия Германии ${ }^{3}$, Демократическая партия Италии ${ }^{4}$, Испанская социалистическая рабочая партия, Французская социалистическая партия 5 заметно ухудшили свои результаты на последних национальных выборах, перспективы евросоциалистов на выборах 2019 г. выглядят весьма плачевными.

Группа «Европейских консерваторов и реформистов» (ЕКР) партии умеренных евроскептиков «Альянс консерваторов и реформаторов в Европе» (АКРЕ) потеряет 19 ДЕП от «Консервативной партии» Великобритании, которые являлись основной национальной делегацией, а её представитель С. Камаль - сопредседатель этой группы. Исторически группа была создана британскими консерваторами в 2009 г. после того, как они вышли из группы ЕНП. Теперь единственной влиятельной партией в АКРЕ остаётся польская партия «Закон и справедливость» (ПиС), которая имеет вторую по величине делегацию. И хотя АКРЕ достаточно широко представлена в странах - членах Евросоюза, ей будет непросто на предстоящих в 2019 г. выборах сохранить имеющийся результат.

И, наконец, группа «Европа свободы и прямой демократии» (ЕСПД) представлявшая популистскую евроскептическую партию «Альянс за прямую демократию в Европе» (АДПЕ), которая существовала с 2014 по 2016 гг., потеряет 19 ДЕП от «Партии независимости Объединённого Королевства». Второй влиятельной партией в этой группе является итальянская партия «Движение 5 Звезд», которая с учётом исчезновения АЛДЕ, скорее всего, на предстоящих выборах присоединиться к какой-либо другой евроскептической партии.

\section{Предварительные прогнозы результатов европейских выборов 2019 г. Проблема явки}

С момента начала избрания депутатов Европарламента прямым всеобщим тайным голосованием в 1979 г. интерес к этим выборам и, соответственно, явка на них неуклонно снижались. С 1979 по 1994 гг. явка составляла более 50\%: в 1979 г. -61,99\% и в 1994 г. - 56,61\%. В 1999 г. явка впервые оказалась ниже 50\%: 49,51\% и в дальнейшем она продолжала падать сначала до 45,47\% в 2004 г., а затем до $42,61 \%$ в 2014 г.

\footnotetext{
1 Web site of European Parlaiment. Treaty on European Union. URL: https://europa.eu/european-union/sites/ europaeu/files/docs/body/treaty_on_european_union_en.pdf (дата обращения: 21.12.2018 г.).

${ }_{2}$ Web site of European Parlaiment. Group of the Progressive Alliance of Socialists and Democrats. URL: http://www.europarl.europa.eu/elections-2014/en/political-groups/group-of-the-progressive-alliance-of-socialists-anddemocrats (дата обращения: 21.12.2018 г.).

3 Parties and Elections in Europe. URL: http://www.parties-and-elections.eu/germany.html (дата обращения: 21.12. 2018 г.).

${ }_{5}^{4}$ Parties and Elections in Europe. URL: http://www.parties-and-elections.eu/italy.html (дата обращения: 21.12.2018 г.).

${ }^{5}$ Parties and Elections in Europe. URL: http://www.parties-and-elections.eu/france.html (дата обращения: 21.12.2018 г.).
} Научно-аналитический вестник ИЕ РАН, 2018, №6 
Этот феномен объясняется несколькими причинами. Однако наиболее важным является то, что голосование проводится на национальном, а не на европейском уровне, и поэтому зачастую предвыборные дебаты сводятся главным образом к обсуждению национальных проблем. Поэтому многие избиратели голосуют исходя из политической ситуации в стране, не особенно беспокоясь о том, как их голос будет влиять на изменение ситуации в Евросоюзе в целом. Национальные партии чаще всего проводят предвыборную кампанию, не обсуждая с избирателями реальные общеевропейские вопросы и не указывая свою принадлежность к той или иной европейской партии. Система пропорционального представительства, которая действует во всех государствах на европейских выборах, ещё больше затрудняет предсказуемость их результатов. Неслучайно ни одна европартия никогда с 1979 г. не имела абсолютного большинства в Европарламенте. И всё это время правящую коалицию формировали две ведущие европейские партии - правоценристская ЕНП и левоцентристская ПЕС, за одним исключением в 1999-2004 гг. ${ }^{1}$ Но для большинства стран - членов Европейского союза подобного рода «большая коалиция» была, мягко говоря, чужда их сложившимся парламентским традициям.

И наконец, сам Европарламент, как общеевропейский политический институт в силу ограниченности его властных полномочий не выглядел в глазах европейских избирателей таким же влиятельным органом, как их национальные парламенты.

В последнее время с учётом того, что в соответствии со ст. 9а Лиссабонского договора полномочия Европарламента как законодательного органа были приравнены к полномочиям Европейского совета, в том числе в отношении утверждения бюджета Евросоюза, Европарламент получил также право самостоятельно избирать председателя. Кроме того, резко изменившийся международный контекст, обозначивший новые для Евросоюза в вызовы (рост миграции с Ближнего Востока, усиление угрозы исламского терроризма, торговая война с США, так называемая российская угроза, связанная с эскалацией конфликта на границах Украины и якобы имевшем место вмешательством России в европейские выборы ${ }^{2}$ ) также повышают значимость Европарламента, который стал более активно реагировать на эти вызовы, принимая соответствующие заявления. И, наконец, руководство ЕС, обеспокоенное ростом популярности евроскептиков, намерено предпринять все возможные усилия для мобилизации европейских избирателей. Всё это в целом позволяет предположить, что на предстоящих выборах тенденция снижения явки будет, по крайней мере, приостановлена.

\section{Рост популярности правых и левых евроскептиков}

Сегодня в Европарламенте действует леворадикальная группа Европейских левых и зелёных Севера (ПЕЛ/3С), которая включает представителей ряда крайне левых партий, в основном занимающих умеренно евроскептические позиции. Они скептически относятся к нынешнему положению дел в Евросоюзе и призывают к его существенному реформированию, не подвергая при этом сомнению само существование Евросоюза. Ведущей партией является коалиция радикальных левых Греции СИРИЗА, возглавляемая премьер-министром А. Ципрасом. В последнее время ПЕЛ укрепила свои позиции в Чехии (Компартия Чехии и Моравии) $)^{3}$, Германии (Де Линке) $)^{1}$, Франции (Непокорённая Франция) $)^{2}$, Нидерландах (Зелёные

\footnotetext{
${ }^{1}$ В 1999-2004 гг. в ЕП была сформирована правящая коалиция между ЕНП и либералами (в то время это была Европейская партия либеральной демократии и реформ, ЕЛДР). URL: https://www.britannica.com/topic/EuropeanLiberal-Democrat-and-Reform-Partv (дата обрашения: 21.12.2018 г.).

${ }^{2}$ Еврокомиссар предупреждает о вмешательстве России в европейские выборы. Сайт информационного агентства Регнум. 26.09.2018. URL: https://regnum.ru/news/2488994.html (дата обращения: 21.12.2018 г.).

3 Parties and Elections in Europe. URL: http://www.parties-and-elections.eu/czechia.html (дата обращения: 21.12. 2018 г.).
} 
левые) $)^{3}$ и др. Партия имеет реальные шансы увеличить свое представительство в Европарламенте до 55-60 депутатов.

Что касается «радикальных евроскептиков» преимущественно правого толка, которые от крыто призывают, по сути, к разрушению нынешнего Евросоюза и создания вместо него более мягкого объединения европейских стран без серьёзной политической надстройки, сегодня они распылены в ЕП по нескольким группам. Группа «Европа наций и свобод» (ЕНС), которая представляет партию «Движение за Европу наций и свобод» (ДЕНС), сформированную вокруг «Национального объединения» М. Ле Пен (НО, Франция) и «Партии свободы» (ПС, Нидерланды) Г. Вилдерса, объединяет представителей ряда партий, которые с недавних пор вошли в состав правящих коалиций в своих странах. Речь идёт о «Партии свободы» Австрии (ПС) Х.-К. Штрахе и партии «Лига» в Италии М. Сальвини. Налаживаются контакты ДЕНС с партией «Альтернатива для Германии», которая в последнее время заметно улучшила свои электоральные результаты на федеральных и региональных выборах в Германии. Это, несомненно, даёт ДЕНС дополнительные возможности для более успешного выступления на предстоящих выборах в ЕП. Тем более что и брекзит и рост миграции также играют на руку праворадикальным евроскептикам. Поэтому вполне можно ожидать, что ДЕНС увеличит своё представительство до 70-75 ДЕП.

Представители других «праворадикальных» партий представлены в ЕП в группах, которые позиционируют себя как умеренные евроскептики. Речь идёт о «Демократической партии» Швеции и партии «Финны» Финляндии, представители которых входят в группу ЕКР. «Движение 5 Звёезд» (Д53) из Италии, входящее в правительство своей страны вместе с Лигой, входит в группу ЕСПД, которая уже не имеет своей общеевропейской партии, и Д53 на этих выборах придётся искать новую нишу, хотя оно вряд ли присоединится к ДЕНС. Кроме того, в ряде стран - членов Евросоюза действуют вполне успешно праворадикальные партии, которые на сегодня не аффилированы ни с одной общеевропейской партией, например, партия «Йоббик» (Венгрия), занявшая на национальных парламентских выборах 2017 г. второе место ${ }^{4}$, партия «Фламандский интерес» (Бельгия), партии «Конгресс новых правых» и «Правое крыло республики» в Польше и др.

Не совсем понятно будущее партии ФИДЕС, которую возглавляет нынешний премьерминистр Венгрии В. Орбан и которая в настоящее время входит в ЕНП. Но в последнее время В. Орбан и его партия всё больше смещаются вправо, особенно в вопросе миграционной политики Евросоюза, что вызывает явное недовольство лидеров ЕНП и руководства ЕС 5 . Пока руководство ЕНП нацелено сохранить ФИДЕС в своих рядах, но вполне возможно, что в оставшееся до выборов время этот альянс распадётся, и партия Орбана займёт более радикальную по отношению к ЕС позицию.

Подобная фрагментация праворадикальных евроскептиков показывает, что им будет сложно объединиться и сформировать общую группу в ЕП после следующих выборов. Помимо их неприязни к Евросоюзу, в которой они сходятся, у них мало согласия по другим проблемам, стоящим перед современной Европой, включая иммиграцию.

\footnotetext{
${ }^{1}$ Parties and Elections in Europe. URL: http://www.parties-and-elections.eu/germany.html (дата обращения: 21.12. 2018 г.).

${ }^{2}$ Parties and Elections in Europe. URL: http://www.parties-and-elections.eu/france.html (дата обращения: 21.12.2018 г.).

${ }^{3}$ Parties and Elections in Europe. URL: http://www.parties-and-elections.eu/netherlands.html (дата обращения: 21.12. 2018 г.).

${ }_{4}^{4}$ Parties and Elections in Europe. URL: http://www.parties-and-elections.eu/hungary.html (дата обращения: 21.12. 2018 г.).

${ }^{5}$ Web site of News Portal «Hungary Today». Hungarian Press Roundup: Debate on Fidesz and EPP, Macron. URL: https://hungarytoday.hu/hungarian-press-roundup-fidesz-epp-macron/ (дата обращения: 21.12.2018 г.).
} Научно-аналитический вестник ИЕ РАН, 2018, №6 


\section{Ослабление позиций консерваторов и социал-демократов}

Очевидно, что после выборов 2019 г. две основные группы Европарламента (ЕНП и СиД) больше не смогут сформировать в нём правящее большинство. Численность группы СиД значительно сократится. Маловероятно, что она будет иметь более 135-145 депутатов в новом составе Европарламента.

ЕНП, которая долгое время оставалась ведущей политической группой Европарламента (219 ДЕП), также после этих выборов существенно сократит своё представительство, но потери будут меньше, чем у СиД. Она, скорее всего, останется ведущей группой, но её численность будет уже менее 200 ДЕП. Действительно, основные партии - члены ЕНП находятся в упадке, начиная с ХДС/ХСС, которая является ведущей силой народников и представлена в ЕП 34 депутатами. Польская «Гражданская платформа» потеряла статус правящей после парламентских выборов 2015 г., хотя и набрала на них 27\% голосов избирателей. Французские республиканцы впервые не смогли провести своего кандидата во второй тур президентских выборов 2017 г., а на парламентских выборах 2017 г. набрали всего 15,8\% голосов. «Народная партия» Испании в июне 2017 г. вышла из правительства. В результате всего этого численность фракции ЕНП может сократиться примерно на 40 мест и составит не более 180 ДЕП.

С учётом этих прогнозов 180 ДЕП от ЕНП и 135-140 ДЕП от СиД дадут им не более 320 мест, а для того, чтобы иметь абсолютное большинство в новом составе Европарламента необходимо иметь минимум 353 ДЕП.

\section{Перспективы формирования новой правящей коалиции в Европарламенте}

Таким образом, эта новая для ЕП ситуация должна привести к более открытым политическим переговорам между проевропейскими партиями. К участию в них вполне может подключиться ЕПЗ, которая в настоящее время имеет 52 ДЕП. С учётом того, что на недавних выборах в местные органы власти Бельгии, германские земельные органы власти Баварии и Гессена и парламента Люксембурга члены ЕПЗ показали неплохие результаты, партия, даже несмотря на потерю 12 ДЕП из Великобритании, имеет все возможности увеличить свою численность. В этом случае, если представители ЕНП, СиД и ЕПЗ сумеют договориться по ключевым политическим вопросам, создание подобной тройственной коалиции позволит ей получить абсолютное большинство в Европарламенте.

Ещё один вариант новой конфигурации правящей коалиции в ЕП может быть связан с привлечением к переговорам о ней европейских либералов из АЛДЕ.

Во-первых, они уже участвовали в формировании правящей коалиции в 1999-2004 гг. Во-вторых, после ухода англичан (отчего АЛДЕ пострадает меньше всего, т.к. в её группе был всего 1 ДЕП от Великобритании) либералы могут претендовать на то, чтобы стать третьей по численности группой в ЕП после выборов 2019 г. В настоящее время группа АЛДЕ имеет 68 депутатов Европарламента. В последние годы партии - члены АЛДЕ добились неплохих результатов на национальных выборах и сегодня в 7 странах - членах ЕС они возглав-ляют правительства (Бельгия, Дания, Люксембург, Нидерланды, Финляндия, Чехия, Эстония). К группе вполне может присоединиться Итальянская демократическая партия, представители которой в настоящее время входят в группу СиД. В этом случае в новом составе Европарламента АЛДЕ сможет сформировать группу численностью примерно в 100 ДЕП.

Открытым остаётся вопрос о том, к кому присоединяться ДЕП, которые будут избраны от партии «Вперёд, Республика!», которую возглавляет президент Франции, Э. Макрон. Пока что он хранит молчание по этому вопросу, тем более что последние события декабря 2018 г.,

Научно-аналитический вестник ИЕ РАН, 2018, №6 
связанные с массовыми протестами так называемых «жёлтых жилетов», требующих отставки Макрона, заметно осложнили его положение на внутриполитической арене Франции.

\section{О возможных последствиях выборов депутатов Европарламента для будущего Евросоюза}

Скорее всего, в новом составе Европарламента проевропейские силы (ЕНП, СиД, АЛДЕ, ЕПЗ) вновь получат абсолютное большинство, что позволит им сохранить контроль над процессом назначения ключевых фигур в политических институтах Евросоюза (Председатель Европейской комиссии и его заместитель, Верховный представитель ЕС по иностранным делам и политике безопасности, Председатель Европарламента и др.). Это позволит представителям данных партий в течение ещё пяти лет контролировать повестку дня этих органов и проводимую ими политику.

Вместе с тем, рост популярности и представительства евроскептических партий в Европарламенте (ПЕЛ, ДЕНС, ЕКР), а главное приход их представителей в правительства ведущих стран - членов Европейского союза (Австрия и Италия) заметно расширят их возможности влиять на деятельность политических институтов Евросоюза через их представителей в Европейском совете и Европарламенте. Всё это представляет серьёзную опасность для политической и экономической устойчивости этого европейского объединения. Брекзит, миграция, рост терроризма, осложнение отношений ЕС с его ведущим партнёром - США, санкционная война с Россией, рост экономического давления со стороны Китая - всё это новые для Евросоюза вызовы, которые уже в ближайшее время подвергнут его небывалой проверке на прочность. И усиление внутриполитического противостояния внутри ЕС между его апологетами и евроскептиками вряд ли будет способствовать укреплению его единства, необходимого для своевременного и эффективного ответа на указанные вызовы.

\section{Список литературы}

1. Потемкина О.Ю. Европейский парламент 2019: подготовка к выборам. Журнал Совеременная Европа. 2018. №4. С. 35-45. URL: http://www.sov-europe.ru/2018/04-2018.pdf (дата обращения: 21.12.2018 г.).

2. Web site of European People party. URL: https://weber.epp.eu/get_to_know_me.

3. Web site of European Parlaiment. Treaty on European Union. URL: https://europa.eu/ european-union/sites/europaeu/files/docs/body/ treaty_on_european_union_en.pdf (дата обращения: 21.12.2018 г.).

4. Web site of European Parlaiment. Group of the Progressive Alliance of Socialists and Democrats. URL: http://www.europarl.europa.eu/elections-2014/en/political-groups/group-of-the-pro gressive-alliance-of-socialists-and-democrats (дата обращения: 21 декабря 2018 г.).

5. Parties and Elections in Europe. URL: http://www.parties-and-elections.eu/germany.html (дата обращения: 21.12.2018 г.).

6. Parties and Elections in Europe. URL: http://www.parties-and-elections.eu/italy.html (дата обращения: 21.12.2018 г.).

7. Parties and Elections in Europe. URL: http://www.parties-and-elections.eu/france.html (дата обращения: 21.12.2018 г.).

8. Web site of European Parlaiment. European Conservatives and Reformists Group. URL: http://www.europarl.europa.eu/elections-2014/en/political-groups/european-conservatives-and-refor mists-group (дата обращения: 21.122018 г.). 
9. Web site of European Parlaiment. Europe of Freedom and Direct Democracy Group. URL: http://www.europarl.europa.eu/elections-2014/en/political-groups/europe-of-freedom-and-directdemocracy (дата обращения: 21.12.2018 г.).

10. URL: https://www.britannica.com/topic/ European-Liberal-Democrat-and-Reform-Party (дата обращения: 21.12.2018 г.).

11. Еврокомиссар предупреждает о вмешательстве России в европейские выборы. Сайт информационного агентства Регнум. 26.09.2018. URL: https://regnum.ru/news/2488994.html (дата обращения: 21.12.2018 г.).

12. Parties and Elections in Europe. URL: http://www.parties-and-elections.eu/czechia.html (дата обращения: 21.12.2018 г.).

13. Parties and Elections in Europe. URL: http://www.parties-and-elections.eu/netherlands.html. (дата обращения: 21.12.2018 г.).

14. Parties and Elections in Europe. URL: http://www.parties-and-elections.eu/hungary.html (дата обращения: 21.12.2018 г.).

15. Web site of News Portal «Hungary Today». Hungarian Press Roundup: Debate on Fidesz and EPP, Macron. URL: https://hungarytoday.hu/ hungarian-press-roundup-fidesz-epp-macron/ (дата обращения: 21.12.2018 г.).

\section{References}

1. Potemkina O. European Parliament 2019. Европейский парламент 2019: preparation to Elections. Contemporary Europe magazine. 2018. №4. P. 35-45. URL: http://www.soveurope.ru/2018/04-2018.pdf (date of appeal: 21.12.2018).

2. Web site of European People party. URL: https://weber.epp.eu/get_to_know_me (date of appeal: 21.12.2018).

3. Web site of European Parlaiment. Treaty on European Union. URL: https://europa.eu/ european-union/sites/europaeu/files/docs/ body/treaty_on_european_union_en.pdf (date of appeal: 21.12.2018).

4. Web site of European Parlaiment. Group of the Progressive Alliance of Socialists and Democrats. URL: http://www.europarl.europa.eu/ elections-2014/en/political-groups/group-of-theprogressive-alliance-of-socialists-and-democrats (date of appeal: 21.12.2018).

5. Parties and Elections in Europe. URL: http://www.parties-and-elections.eu/germany.html (дата обращения: 21.12.2018 г.).

6. Parties and Elections in Europe. URL: http://www.parties-and-elections.eu/italy.html (date of appeal: 21.12.2018).

7. Parties and Elections in Europe. URL: http://www.parties-and-elections.eu/france.html (date of appeal: 21.12.2018).

8. Web site of European Parlaiment. European Conservatives and Reformists Group. URL: http://www.europarl.europa.eu/elections-2014/en/political-groups/european-conservatives-and-refor mists-group (date of appeal: 21.12.2018).

9. Web site of European Parlaiment. Europe of Freedom and Direct Democracy Group. URL: http://www.europarl.europa.eu/elections-2014/en/political-groups/europe-of-freedom-and-direct-de mocracy (date of appeal: 21.12.2018).

10. URL: https://www.britannica.com/topic/ European-Liberal-Democrat-and-Reform-Party (date of appeal: 21.12.2018).

11. The European Commissioner warns of Russia's Interference in the European Elections. The website of the information Agency REGNUM 26.09.2018. URL: https://regnum.ru/news/2488994. 
html (date of appeal: 21.12.2018).

12. Parties and Elections in Europe. URL: http://www.parties-and-elections.eu/czechia.html (date of appeal: 21.12.2018).

13. Parties and Elections in Europe. URL: http://www.parties-and-elections.eu/netherlands. html (date of appeal: 21.12.2018).

14. Parties and Elections in Europe. URL: http://www.parties-and-elections.eu/hungary.html (date of appeal: 21.12.2018).

15. Web site of News Portal «Hungary Today». Hungarian Press Roundup: Debate on Fidesz and EPP, Macron. URL: https://hungarytoday.hu/hungarian-press-roundup-fidesz-epp-macron/ (date of appeal: 21.12.2018).

The pan-European Elections 2019: Preliminary Forecasts and Possible Prospects

Author. Guseletov Boris, Doctor of Sciences (Politics), Senior Research Associate, Center for Party and Political Studies, Institute of Europe, Russian Academy of Sciences. Professor of the Specialized Department of IE RAS in the Russian State Social University. Address: 11-3, Mokhovaya str., Moscow, Russia, 125009.E-mail: bgusletov@mail.ru.

Abstract. In May 2019, the EU countries will hold regular elections of deputies of the European Parliament - the main representative body of the Union. Taking into account a number of recent high-profile events that shook the EU, including Brexit, the coming to the leadership of eurosceptic and populist forces in a number of EU member States (Austria, Hungary, Italy, Poland), the aggravation of relations with both the former main partner of the EU - the United States, and with a constant opponent in the face of Russia, the results of these elections are unpredictable. In this article, the author analyzes the possible impact of these events on the results of the upcoming elections and tries to give a preliminary forecast of their results.

Key words: European Union, European Parliament, European parties, European elections, Brexit, Spitzenkandidat.

DOI: http://dx.doi.org/10.15211/vestnikieran620184754 